\title{
INCORPORAÇÃO DO LADO MAR À GEOGRAFIA DAS METRÓPOLES NORDESTINAS
}

\author{
INCORPORATION OF THE SEASIDE INTO THE GEOGRAPHY OF \\ NORTHEASTERN METROPOLISES
}

\author{
L'INTÉGRATION DE LA MER À GÉOGRAPHIE DES MÉTROPOLES DU \\ "NORDESTE" BRESILIEN \\ Eustógio Wanderley Correia Dantas - Universidade Federal do Ceará - Fortaleza - Ceará - Brasil \\ ewcdantas@gmail.com
}

\section{Resumo}

0 artigo discute, a partir do entendimento do delineamento das práticas marítimas no Brasil, a lógica de urbanização litorânea empreendida no final do século XX e início do século XXI no Nordeste. Lida, nestes termos, com a prática da vilegiatura marítima e do turismo litorâneo, responsáveis pela implementação do fenômeno de metropolização a direcionar as principais metrópoles nordestinas (Fortaleza, Natal, Recife e Salvador) as suas zonas de praia.

Palavras-chave: Metrópole, Nordeste, turismo, vilegiatura, lazer, maritimidade.

\section{Abstract}

From the understanding of the concept definition of maritime practices in Brazil, this article discusses the logic of coastal urbanization undertaken in the late $20^{\text {th }}$ century and early $21^{\text {st }}$ century in the Northeast. It addresses the maritime vacation and coastal tourism, which are responsible for the metropolization phenomenon that directs the major Northeastern metropolises (Fortaleza, Natal, Recife and Salvador) toward their seaside.

Keywords: Metropolis, Brazilian Northeastern region, tourism, vacationing, leisure, maritimity.

\section{Résumé}

Prenant en compte la logique de caracterisation des pratiques maritimes au Brésil, I'article en question analise I'urbanisation côtière, entreprise à la fin du XX-début du XXI siècle, au Brésil. Dans cette perspective, il indique la pratique de la vilegiature maritime et du tourisme côtier comme fort responsable de la mise en œuvre d'un phénomène de métropolisation qui a tourne les grandes villes du Nordeste (Fortaleza, Natal, Recife et Salvador) vers leurs zones de plage.

Mots-clés: Metropole, Nordeste, tourisme, vilegiature, loisirs, maritimite.

\section{Considerações Iniciais}

Compreender a instituição das cidades litorâneas nordestinas, vis-à-vis a valorização de suas zonas de praia, conduz à utilização de esforço analítico focado no lazer. Variável preponderante no entendimento do fenômeno de urbanização (Lefebvre, 1986), ocupa destaque no campo dos desejos, das expectativas e das frustações reinantes na sociedade ocidental (Corbin, 2001). Analisando as práticas marítimas modernas, 
Corbin (1988) empreendeu análise diacrônica sobre os desdobramentos do tempo social nas zonas de praia do Mediterrâneo. Mesmo atualmente, em outros continentes e países, a força de seu trabalho ecoa, sendo possível vislumbrar a gestação de um conjunto de imagens estereotipadas das zonas de praia no mundo, ou mesmo de um "território do vazio tropicalizado”, na expressão de Cormier-Salem (1996). Convém destacar que o exagero analítico comentado não se encontra em Corbin (1988). Embora não reste dúvida que as práticas marítimas modernas repousam suas raízes no Ocidente, o seu lido em outras paragens requer desenvolvimento de estudos capazes de apreender as ressignificações pelas quais passam.

A citada premissa é buscada no entendimento do processo de metropolização das cidades mais dinâmicas do Nordeste (Fortaleza, Natal, Recife e Salvador), com ênfase no final do século XX e início do século XXI. A intensa modificação da paisagem urbana dessas cidades resultou na valorização das zonas de praia, aumentando a integração entre os municípios costeiros metropolitanos e não metropolitanos. Nesse processo de incorporação, destacamos dois momentos: i) aproximação da sociedade local em relação ao mar, pautado nas escalas das cidades litorâneas e das metrópoles litorâneas. ii) transformação das cidades litorâneas nordestinas em marítimas, leia-se turísticas, o que resultou na aumento dos fluxos (pessoas, capitais etc.) nas escalas nacional e internacional.

\section{Incorporação do mar à geografia das cidades}

O primeiro momento, referente à aproximação inicial da sociedade local em relação ao mar, se deu a partir de ruptura com modelo clássico de urbanização das cidades litorâneas. Essas cidades passaram por uma significativa valorização do "seu lado mar", o que implicou na instrumentalização das faixas de praia (e regiões próximas), com o estabelecimento de fortes, entrepostos e portos (Desse, 1996).

Mesmo considerando o evidenciado, convém destacar que, grosso modo, as zonas de praia se instituíam como reino quase exclusivo das práticas marítimas tradicionais: a portuária, a marinha nacional (defesa), bem como a pesca artesanal. Somente no final do século XIX e início do século XX, nota-se uma ruptura da racionalidade apresentada, suscitando os primeiros passos da sociedade local em relação às zonas de praia. A condição de cidades comerciais não somente permitiu a exportação de 
mercadorias nobres à Europa. Nos portos, atendendo às demandas das elites locais, o volume de bens materiais importados era significativo e deixava espaço aberto à assimilação de novos hábitos e leituras em relação ao mar.

A assimilação mencionada suscita o delineamento das práticas marítimas modernas no Brasil e em processo que as ressignificam, gestando práticas vizinhas às do Ocidente (Dantas, 2014), a exemplo dos banhos de mar e das caminhadas nas praias no país. Se no concernente aos tratamentos terapêuticos no Ocidente, a qualidade química e a temperatura do mar são variáveis fundantes, nos Trópicos as águas mornas conduzem o redimensionamento do discurso médico, e consoante com a teoria do "bem respirar" de Lavoisier (Corbin, 1988). Se as caminhadas na praia, do Gênero do "Promenades Anglais", aconteciam durante o dia e aproveitando as temperaturas amenas do mediterrâneo, nas regiões próximas ao Equador, com ação dos raios solares perpendicular ao solo, acontecem nos finais de tarde e em noites de lua cheia (Dantas, 2004). A localização geográfica tornou inviável a simples transposição das práticas marítimas modernas importadas do Ocidente.

No processo de ressignificação das práticas marítimas modernas, a elite local, composta em vivo processo de miscigenação (Claval, 1995), exerce papel de destaque. Em processo de ocidentalização pelo qual passou o país, os mestiços tiveram um papel central na filtragem estabelecida na região e vis-à-vis a vivência experimentada em ambientes não litorâneos: no sertão, na zona da mata e no recôncavo. Referimo-nos à existência de seres interioranos moldados na aproximação em relação ao mar, e lenta e gradualmente aos padrões, hábitos e valores do velho mundo.

A citada elite se fez representante dos bons costumes e em contraponto àqueles que se nutriam das práticas marítimas tradicionais, denotando um embate entre autóctones (uma elite ocidentalizada e os habitantes tradicionais das praias). Tal fenômeno fica circunscrito aos limites das cidades-sede, percebendo-se claramente a imposição da escala da cidade nos conflitos estabelecidos nas zonas de praia e a suscitar transformações substanciais na estrutura urbana, com a ocupação das zonas de praia de Fortaleza (Praia de Iracema) (Dantas, 2011), Natal (Praias da Rendinha e Areia Preta)(Silva, 2013), Recife (Praia de Boa Viagem) (Freyre, 1934; Assis, 2003) e Salvador (Praia do Rio Vermelho)(Vasconcelos, 1997; Sousa, 2011; Silva, 2011; Wendel, 2011) pela vilegiatura marítima. 
A vilegiatura adquiriu papel central no delineamento dos banhos de mar (terapêuticos e recreativos) e das caminhadas no Nordeste. De uma priorização de outras parcelas do território para seu exercício (sítios e chácaras no sertão, agreste e nas serras), a invenção das praias no Nordeste se ressignifica diante da valorização do mar no imaginário social. Daí a construção da maritimidade no Nordeste tomar um caminho diferenciado, não associado às estações balneárias, mas à necessidade de aquisição de uma segunda residência para o exercício dos banhos de mar e das caminhadas. A vilegiatura explicaria e justificaria a incorporação inicial das zonas de praia.

Os limites das cidades em foco são respeitados até a primeira metade do século XX. A exclusividade delas cai por terra a partir dos anos 19601970, com a instituição da cidade moderna, que se torna policêntrica e aponta a sua instituição como metrópole, em articulação com seus municípios vizinhos.

No entendimento do processo de transformação da cidade em metrópole, a parcela litorânea desempenha papel estratégico, associado aos domínios da habitação e do lazer representativos: i) das classes mais abastadas que estabelecem na praia suas primeiras residências (Claval, 2004). Somam-se, portanto, aos vilegiaturistas e, com o tempo, os suplantam em número. A força do desejo de morar permanentemente de frente ao mar é a mola motriz da lógica de valorização do mercado de terras, com estabelecimento de intenso processo de verticalização, pós anos 1960-1970, em áreas litorâneas das cidades de Fortaleza (Praia do Meireles), Natal (Ponta Negra), Recife (Boa Viagem) e Salvador (Rio Vermelho). Os referidos bairros tendem a se constituir como lócus de habitação do citado segmento, inicialmente com a transformação de segundas residências em primeiras residências e, na sequência, com a construção de arranha-céus para estabelecimento de condomínios residenciais; ii) de empreendedores no ramo do lazer, que transferem as sedes de seus clubes às praias. Vis-à-vis a atração exercida pelo mar em relação à sociedade, passam a concentrar um conjunto de atividades recreativas e de lazer, anteriormente condizentes com o centro tradicional. Os clubes sociais migram à praia, passando a oferecer infraestrutura balizadora das práticas marítimas modernas, tanto as já citadas anteriormente como as de caráter esportivo (natação) e náutico (marinas); iii) de empreendedores do ramo hoteleiro, a também migrarem às praias urbanizadas das cidades em foco, que se especializam na recepção de fluxos 
representativos dos primeiros turistas a frequentarem a região. Resulta dos ensaios pioneiros dos governos locais em desenvolver a atividade turística na região (Ferreira, 2013) e cujo desdobramento somente se efetivou plenamente em Salvador, instituída desde então como cidade turística; iv) de usuários diversos, das classes abastadas e da classe média principalmente, a elegerem as praias como lócus de sociabilidade. Nestes termos, usufruem dos calçadões a acompanharem paralelamente as praias, em padrão de urbanização diferenciado do característico das praças centrais: quadrangular. Seu padrão linear permite a incorporação da totalidade da praia, podendo seus usuários caminhar (admirando a paisagem), se dedicar aos banhos de mar e de Sol e usufruir de um conjunto de serviços em restaurantes, bares, fast-food, lanchonetes, sorveterias, lojas de artesanatos etc.

A zona costeira dos municípios próximos, aqueles a comporem as regiões metropolitanas, tem uma sorte diferenciada. Neles, com a construção de segundas residências, o lazer reina em absoluto e em concorrência com as práticas marítimas modernas, principalmente a pesca artesanal. A urbanização dos distritos litorâneos situados nos municípios de Aquiraz (Ceará); Nísia Floresta (Rio Grande do Norte); Itaparica (Pernambuco) e Itamaracá (Bahia) resultam da citada demanda e representam articulação estabelecida pela metrópole com o mar. Implica, sobremaneira, na consolidação de um modelo gestado nas capitais e a encampar a escala regional.

Como fenômeno demandador de infraestrutura, a atividade turística requer ampliação da estrutura urbana na franja litorânea (zonas de praia), a ponto de ser mencionado por Pereira (2012) como vetor de constituição da região metropolitana no Nordeste. Indica-se quadro diferente do apresentado por Moraes (2007) ao associar lógica de crescimento urbano das cidades litorâneas nos anos 1950 ao simples estabelecimento das indústrias nas zonas portuárias.

No Nordeste o papel do setor terciário não pode ser negligenciado, especialmente o resultante da ação do poder público, por intermédio dos bancos e instituições de pesquisa e fomento às atividades produtivas, importantes na formação da classe média local. O citado segmento, demandador de segundas residências, reverte o caráter elitista da vilegiatura marítima. Para tanto conta com o Estado no financiamento do imóvel pelo antigo BNH e na urbanização das zonas de praias.

Nessa perspectiva, antigos espaços de vilegiatura nas capitais são substituídos por espaços de moradia e de lazer, e o uso ocasional das zonas 
de praia das capitais perde importância em relação ao uso permanente. Morar na praia se constitui em objeto de desejo e, reforçado pelo mercado imobiliário, redimensiona esses espaços e induz, concomitantemente, incorporação de antigas áreas ocupadas por populações tradicionais à vilegiatura marítima.

A incorporação do mar à geografia das metrópoles em foco não significou, no entanto, a reversão do quadro imagético associado a elas. Elas guardam a essência das cidades litorâneas-interioranas, cujas representações coletivas reinantes continuavam associadas ao continente, com ênfase ao sertão, e reforçavam, pautado em discurso de caráter determinista, a tese conhecida do Nordeste brasileiro como "região problema".

Os fatores elencados têm implicações no delineamento de políticas públicas de caráter regional, concentradas em esforços de industrialização e destoam, nestes termos, das políticas adotadas em outros países da América Latina, cuja base natural validou, no Pós-Guerra, a atividade turística litorânea. Para os planejadores brasileiros, a atividade turística, considerada de pouca relevância, seria justificável somente em micropaíses (ilhas). Na melhor das hipóteses, houve tentativa dos governantes locais em disponibilizar às populações de seus estados, quiçá da região, uma proposta de turismo associada à história do lugar e à cultura do povo (Ferreira, 2013).

$\mathrm{O}$ cenário apresentado somente foi revertido no final século $\mathrm{XX}$, como reflexo de transformações de caráter político ocorridas no Nordeste e em resposta a uma nova ordem política nacional e internacional. Remete-se à Crise do Estado Moderno, com implementação de uma nova constituição e geração de um quadro no qual os governos dos estados nordestinos, Estado Local (Claval; Sanguin, 1997), adquirem autonomia na construção de políticas públicas de desenvolvimento. Atualmente, os governantes dos estados nordestinos tomam para si a idealização e o controle das políticas de modernização. Passam a dialogar no sentido de captar investimentos, diretamente com organismos internacionais de desenvolvimento, como o Banco Interamericano de Desenvolvimento (BID), e empreendedores privados (nacionais e internacionais). $\mathrm{O}$ poder do governo central é minimizado, atuando somente como avalista dos empréstimos realizados pelos Estados Locais.

O segundo momento, relativo à transformação das cidades litorâneas nordestinas em marítimas, se impõe, colocando em cena a racionalidade de intervenção gestada pelos governantes da região, em política circunscrita 
nos limites dos estados e pautada na potencialidade do substrato natural. A natureza se apresenta, portanto, como premissa na construção do imaginário sociopolítico regional (Castro, 1997), dado a justificar sua utilização como recurso ideológico das elites políticas. As elites tradicionais souberam utilizar o recurso citado com competência, cabendo às novas, ascenderem ao poder no final do século XX, com a necessidade de elaboração de um discurso diferenciado e voltado à legitimação de nova política de desenvolvimento.

A construção da cidade litorânea-marítima (Dantas, 2011b) pode ser interpretada pela passagem de uma compreensão da visão negativa do Nordeste para uma matriz política econômica que buscou a reversão dessas mesmas imagens negativas construídas a partir de uma visão específica do semiárido nordestino. Ela se materializa em um contexto, final dos anos 1980 e início dos anos 1990, favorável à implementação de políticas públicas voltadas à constituição desta parcela do território em região turística (Ferreira, 2013).

O tratamento dado por essas novas elites regionais culminou em fragmentação da região, com direcionamento econômico a privilegiar parcelas do espaço. Metaforicamente forjam-se dois Nordestes: o Nordeste Turístico e o do Agronegócio (Dantas et al., 2006b), respectivamente responsáveis pela reinvenção do litoral e do Sertão (suas zonas de várzea, tabuleiros e cerrado).

O Nordeste Turístico, objeto de nossa análise, deriva de política de desenvolvimento voltada à conversão do litoral em zona turística. A citada atividade se apresenta como poderoso instrumento argumentativo colocado a serviço da região e, consequentemente, capaz de salvar sua economia. No discurso concebido pelos governantes e assessores de alto escalão, as altas temperaturas e a pouca incidência de chuvas (concentradas no tempo e no espaço) seriam um atributo positivo na atração de fluxos turísticos.

A política pública em foco se fundamenta em uma consciência turística a refletir nos novos governos nordestinos. Ela se revela propaganda política e se transmuta em publicidade, para atender aos termos do desenvolvimento econômico e propalar a modernização tão almejada das zonas de praia. É nestes termos que, pautado na ideia da ação conjugada publicidade-propaganda de Domenach (1979), compreendemos como se dá a construção da imagem turística das cidades nordestinas, fundamentada 
em suas vantagens climáticas, focada no sistema mundo e a objetivar a modernização do Nordeste e, por conseguinte, apagar a imagem trágica do imaginário social da seca.

Nesses termos o turismo se apresenta como um dos mais importantes vetores de desenvolvimento da região, sendo balizado por programas voltados ao turismo litorâneo (PRODETUR I E II). A espacialização dos investimentos desses programas na zona costeira, embora esboçada conforme cada um dos governantes considerados, segue um padrão de: a) reforço do Nordeste como destinação turística litorânea, o turismo de sol e praia; b) ressignificação das cidades-sede nordestinas como ponto de recepção e distribuição dos fluxos turísticos.

O padrão clássico da política turística empreendida no Nordeste visava a atrair empreendimentos (hoteleiros e resorts) e captar fluxos turísticos internacionais. As cidades-sede e as zonas de praia dos municípios litorâneos desempenham papéis diferenciados neste constructo. As primeiras se especializam no receptivo, concentrando aeroportos (exceto Rio Grande do Norte, com dinâmica metropolitana) e hotéis. As segundas se alimentam dos fluxos de turistas e do estabelecimento de resorts.

Essa política turística culminou na efetivação da lógica de modernização contemporânea e baseada numa dinâmica que não se explica fora da articulação dos aeroportos com as vias litorâneas, explicando o gênero de urbanização a acompanhar paralelamente a zona costeira e que representa uma densificação maior de investimentos nos ares metropolitanos (somatório do Prodetur I e II) e o espalhamento das intervenções em número maior de municípios litorâneos (Prodetur II). A citada difusão acaba reforçando o peso do metropolitano na região, à medida que aponta priorização da metrópole e de sua região metropolitana nas áreas de intervenção. A política turística, além desses domínios, se explicaria pela: a) constituição de novos núcleos turísticos no próprio Estado, como na Bahia nos casos de Ilhéus e Porto Seguro; b) criação de destinações turísticas em escala regional, a exemplo do acordado entre Ceará, Piauí e Maranhão nos termos do projeto CEPIMA; c) demandas crescentes das municipalidades litorâneas ávidas em participar do fato turístico.

O êxito das políticas públicas é evidente, entretanto não significa dizer que o objetivado se consolidou como propalado. Embora a visão empreendida pelos governantes seja estratégica e inovadora, novas variáveis foram incorporadas por novos usuários e empreendedores. No domínio 
dos fluxos internacionais, os governantes foram surpreendidos pela importância que o turismo nacional adquiriu na região. Ele hoje representa o forte do contingente envolvido e valida os investimentos realizados na região. Da busca pelo internacional se redescobre a pujança do nacional, tanto com fluxos provenientes de outras regiões e estados brasileiros, como os de caráter eminentemente regional (Dantas, 2012). No domínio da busca por empreendimentos clássicos, percebe-se crescimento do setor hoteleiro com implementação na região e principalmente nas metrópoles, de cadeias de hotéis nacionais e internacionais, bem como um número não negligenciável de resorts nas zonas de praia dos municípios litorâneos, com ênfase maior nas regiões metropolitanas e menor nos demais municípios da zona costeira. Esta proliferação de empreendimentos foi importante no fortalecimento do turismo receptivo na região, mas usuários invisibilizados acabaram se impondo, especificamente o grande número de vilegiaturistas provenientes do estrangeiro. Isso se justifica tanto pela validação da prática da vilegiatura marítima como pelos empreendedores imobiliários associados ao turismo. Da lógica clássica da vilegiatura, a envolver escala local, percebe-se, com a saturação dos espaços à vilegiatura marítima nos países desenvolvidos (Boyer, 2008), a descoberta das paragens do Nordeste por estrangeiros.

A chegada de novos usuários, vilegiaturistas alóctones internacionais, não foi pensada pelos gestores públicos. O viés clássico da política turística acabou cegando-os. Foram os empreendedores locais associados aos internacionais (portugueses, italianos e espanhóis) que vislumbraram a virtualidade econômica do fenômeno. Eles buscam, a partir desta associação, inserir-se no mercado internacional ávido por espaços de vilegiatura.

Os empreendedores mencionados diversificam o cenário das opções econômicas nos estados nordestinos, notadamente no domínio imobiliário. Para tanto dispõem de trunfos, o acesso a terra, com infraestrutura urbana, e recursos financeiros necessários à implementação de empreendimentos. No mais, são esses atores, ao ocuparem a cena política, os responsáveis pela sensibilização dos governos nordestinos na participação nas feiras internacionais do setor.

O que se diferencia na teoria (turismo e vilegiatura), na prática dos empreendedores se complementa. Como analisado em Dantas (2015), os empreendedores, de um lado, utilizam das segundas residências, principalmente na alta estação, para aumentar o número de leitos disponíveis 
no complexo turístico. De outro lado, ao apresentarem a possibilidade de inclusão das segundas residências no pool hoteleiro, auferem uma renda ao proprietário da segunda residência. $\mathrm{O}$ citado ponto de partida conduz colegas espanhóis a direcionar uma análise ao que intitulam de Turismo Residencial (Andreu, 2005; Aledo, 2008; Nieves, 2008; Demajorovic et. al., 2011; Munoz e Timon, 2011; Torres Bernier, 2003).

No entanto, com a crise internacional os intentos iniciais são revisitados. O consumidor almejado (vilegiaturista internacional), assim como o volume de investimentos, rareia. Em contrapartida, após 2009, os empreendedores imobiliários alteram sua política de marketing, direcionando-a ao mercado nacional, e redimensionam, em tamanho, os projetos. Mais uma vez, e replicando o acontecido no turismo, a base responsável pela geração de fluxos a evitar uma crise no setor, a exemplo do ocorrido na Europa e Estados Unidos, foi a clientela local: nacional, regional, bem como segmentos das elites locais.

É a partir desse movimento nacional e regional que o quadro característico de ocupação dos espaços litorâneos no Nordeste é modificado. Inicialmente com a chegada de vilegiaturistas alóctones a usufruírem das praias nordestinas. Este segmento, proveniente do país e em menor número do estrangeiro, inova e diversifica a dinâmica de ocupação dos espaços litorâneos. Este segmento, igualmente, demanda infraestrutura, diferentemente do que se verificou nos primórdios da vilegiatura marítima. Diversifica por encampar em suas áreas de estabelecimento parcela de espaços mais amplos do que os atualmente valorados pela elite local e classe média. Esses se estabelecem tanto nas cidades-sede, privilegiadas pelos segmentos mais abastados como lócus de moradia permanente, como nas praias dos demais municípios litorâneos. O que conta para este segmento é a ambiência marítima característica, também, das cidades-sede.

\section{Inserção das cidades nordestinas no sistema mundo}

Embora seja óbvio que a força do desejo pelo mar, com incorporação crescente das atividades de lazer e recreação nos espaços litorâneos, deixe marcas profundas na paisagem urbana, não podemos esquecer que seus desdobramentos se diferenciam de continente a continente e de país a país.

Lidando no nível das especificidades, tal lógica é vislumbrada em dinâmicas características de dois grandes blocos de países: dos pioneiros 
e dos atingidos pelo fenômeno de "internacionalização" das práticas marítimas modernas. O primeiro bloco concentra países ocidentais, com ênfase na região do Mediterrâneo (Europa Ocidental) (Corbin, 1988); nos estados da Califórnia e Flórida, nos Estados Unidos (na América do Norte) (Boyer, 1996; Nijman, 2010). O segundo bloco representa uma abertura ao mundo e a contemplar, também, os países do Sul, em vivo processo de ocidentalização.

Nas Américas constatamos a existência de quadro complexo, tanto com a presença de países ocidentais (Estados Unidos e Canadá) como de ocidentalizados. O primeiro grupo de países consolida em seus territórios as práticas marítimas modernas pari passu a de seus pares na Europa Ocidental. O segundo as consolidam a partir de dois gêneros de filtragens diferenciadas e em relação aos quais gravitam: i) demanda de natureza externa - proveniente do Ocidente e associada à descoberta dos litorais tropicais por amantes de praia, tanto turistas como vilegiaturistas internacionais (Desse, 1996; Cormier-Salen, 1996; Boyer, 2008); ii) demanda de natureza interna - justificada em processo intenso de ocidentalização pelo qual passam os Países do Sul. Trata-se, nos termos indicados por Claval (1995), da sedução que o modelo ocidental exerce sobre as elites e classes médias locais.

Os países (ilhas, inclusive) a gravitarem mais próximo da primeira dinâmica, com políticas de desenvolvimento derivadas de demandas externas por lugares turísticos, se situam nas Antilhas e América Central. Nessa parcela do território americano encontramos o sistema político (governos locais) associado ao sistema comercial (das agências de viagem e das empresas aéreas) (Cazes, 1999), responsáveis pela implementação da política de planejamento transformadora de países em destinações turísticas internacionais. Os países constituem-se em lócus privilegiado do turismo litorâneo nas Américas e a se beneficiam das inovações do transporte aéreo (Chardon, 1987).

O Brasil gravitava próximo à segunda dinâmica, representando o bloco no qual o turismo internacional não se institui. Focada em esforço de industrialização, a política de modernização adotada no país foi o alicerce para formação de uma base de consumidores (a elite e as classes médias) ávidos por espaços de lazer e recreação. Seduzidos pelo Ocidente, o Brasil empreendeu procedimentos de incorporação de práticas marítimas modernas vizinhas àquelas da Europa Ocidental (Dantas, 2004), 
justificando, portanto, a consolidação de uma vilegiatura marítima e a geração de fluxos turísticos litorâneos de caráter fortemente nacional.

Remeter a países gravitando entre dois extremos, permite vislumbrar um quadro complexo de países a adotarem políticas de caráter misto, bem como daqueles cujos posicionamentos mudam no tempo. No primeiro caso nos referimos ao ocorrido no México, país posicionado em situação intermediária, ao usufruir tanto dos fluxos turísticos internacionais como derivado da elite local e de uma classe média em formação (Kadt, 1979). Tal lógica não se justifica em relação a uma demanda isolada, seja ela: i) alóctone, posta no cerne das transformações urbanas, amantes de praia locais, influenciados pelo padrão ocidental e beneficiados pelas políticas sociais (férias remuneradas), abundam nos lugares turísticos (Evans, 1979); ii) autóctone, haja vista se beneficiarem da proximidade em relação aos Estados Unidos e Canadá, captando fluxo de turistas e vilegiaturistas. No segundo caso, percebemos, em países como o Brasil, o redimensionamento das políticas de modernização, com a consequente incorporação do turismo como variável de desenvolvimento. Embora tardiamente, se comparado a vários países do continente, com políticas implementadas no pós-guerra, a meta de consolidação do país como destinação turística internacional modifica a política de ordenamento regional.

Suplantar leitura pautada em dinâmicas antagônicas, e assimilar princípio fundante de níveis de gradação a oscilarem entre uma tônica de valorização alóctone e autóctone, com rebatimento diferenciado de país para país e mutável no tempo, permitem compreender os desdobramentos hodiernos das políticas de desenvolvimento do turismo no Brasil, com seus impactos nas principais metrópoles do Nordeste do Brasil e suas respectivas regiões metropolitanas.

Tomando como pressuposto a apreensão deste processo de ocidentalização empreendido no Brasil, cujo reflexo é percebido nas práticas culturais e na relação com as áreas de praia, por exemplo, tornar-se-á possível compreender como de região produtora de alimentos e, mais recentemente, industrializada, o Nordeste é reinventado como destinação turística. Movimento tributário da força que o desejo pelo mar adquire em escala planetária, não é por acaso que a vilegiatura marítima e o turismo litorâneo se tornam, portanto, vetores de intensificação de lógica de urbanização empreendida nas zonas de praia das metrópoles e de suas regiões metropolitanas (Dantas, 2013). 
A revisão da tese da transposição das práticas marítimas modernas, inventadas no Ocidente, para os trópicos (antigas colônias europeias) se impõe, embora importante número de estudiosos ainda insista em evidenciar transformações induzidas pelo mesmo padrão notado na Europa. De um lado, estudiosos brasileiros como Linhares (1992) e Gomes (2002) a insistirem no efeito de moda suscitado por atores estratégicos no país, respectivamente D. Pedro II e a atriz Sarah Bernard. Pioneiros no estabelecimento das práticas marítimas modernas no Brasil, reforçam o fluxo de informações que modificam as representações coletivas da sociedade em relação ao mar e assumem, guardando as proporções, o mesmo papel desempenhado por seus pares na Europa. De outro lado, estudiosos não brasileiros como Desse (1996) e Cormier-Salen (1996) tratam o litoral como espaço de conflito entre uma maritimidade moderna (alóctone) relativa às demandas dos ocidentais e outra tradicional (autóctone) relacionada aos habitantes tradicionais.

Os dois gêneros de abordagem auxiliam na aproximação do fenômeno em foco, entretanto, e no caso do Brasil, as práticas marítimas modernas não são incorporadas impunemente. Percebe-se tanto a filtragem realizada pelos lugares em relação às inovações (Santos, 1985) como a mutabilidade da cultura, reflexo do posicionamento dos indivíduos em relação às influências externas (Claval, 1995).

A cidade litorânea de outrora perde força. A metrópole emergente passa a incorporar gradualmente as zonas de praia da região metropolitana à sua geografia e não podemos, consequentemente, compreender esse fenômeno sem tratar da atual valorização do litoral como espaço de lazer e turístico.

Os usuários, amantes de praia, esboçam um mundo novo e pautado por múltiplas escalas. Dos que habitam a metrópole e, a partir dela, materializam seus desejos por uma segunda residência em outros municípios litorâneos (vilegiatura marítima autóctone), daqueles em viagem, animados em conhecer as paragens marítimas do Ceará (turismo litorâneo). Dos confundidos com turistas, os vilegiaturistas, cujo anseio é o de fixar residência ocasional na praia e, inclusive, na metrópole (vilegiatura marítima alóctone). Para os turistas, o estado investe em infraestrutura e políticas de atração. Para os vilegiaturistas nada desse gênero foi pensado. Entretanto, convém ressaltar que eles também se beneficiaram da infraestrutura turística, sendo o aumento de seu contingente (provenientes 
de outros estados brasileiros e do estrangeiro) alicerce à emergência de empreendimentos imobiliários.

A incorporação do mar à geografia das cidades litorâneas do Nordeste transformou, lenta e gradualmente, suas zonas de praia. Na contemporaneidade atinge nível de refinamento com a construção de infraestrutura urbana derivada de investimentos públicos, que além da atividade turística justificam empreendimentos imobiliários nacionais e internacionais (Dantas, 2013).

Com o advento da sociedade dos lazeres em constituição, as cidades litorâneas nordestinas se tornam marítimas, validadas pelo exercício recente das práticas turísticas e da vilegiatura marítima: projetam-se, portanto, em escala internacional, participando do pool de cidades a valorarem seu lado mar.

\section{Considerações finais}

Do evidenciado anteriormente, compreende-se como a paisagem urbana litorânea característica do Nordeste de tempos pretéritos, com cidades a darem as costas ao mar, muda completamente na atualidade. Elas adquirem ares de metrópole, se projetam plenamente à suas zonas costeiras e, grosso modo, em resposta a demandas por espaços de lazer e recreação, a representarem e legitimarem o espalhamento das práticas marítimas modernas (os banhos de mar terapêutico e recreativo, a vilegiatura marítima e, nos últimos decênios, o turismo litorâneo associado ao imobiliário) na escala planetária.

O forte fenômeno de verticalização constante nos principais bairros litorâneos das metrópoles em foco, a construção de vias costeiras ligando-as às suas regiões metropolitanas, bem como a intensificação do processo de urbanização notado nos distritos litorâneos dos demais municípios metropolitanos, denotam um quadro a explorar e se justificar na instituição das práticas marítimas modernas no país e em sua relação com o sistema mundo. Apresenta-se tônica de incorporação do mar à geografia das cidades e pautada em processo de urbanização dispersa, cujas características marcantes são a: i) Linearidade, ditada por dinâmica a acompanhar paralelamente a zona costeira; ii) Fragmentação, representativa de urbanização não contínua e focada em algumas parcelas do território metropolitano: iii) Sazonalidade, reflexo de uso derivado de 
práticas materializadas em períodos específicos do ano: a turística na alta estação e a da vilegiatura em período mais longo de tempo.

\section{Referências}

ALEDO, A. De la tierra al suelo: La transformación Del paisaje y el Turismo Residencial. Arbor Ciencia, Pensamiento y Cultura, Madrid, v. 184, n. 729, 2008.p. 99-113

ANDREU, H. G. Una cercamiento al concepto de Turismo Residencial. In: MAZÓN, T.; ALEDO, A. (Org.). Turismo residencial y cambio social: nuevas perspectivas teóricas e empíricas. Alicante: Universidad de Alicante, 2005.

ASSIS, L. F. Turismo de segunda residência. Revista Território, Rio de Janeiro, v. 11-13, 2003.p. 107-122.

BANCO DO NORDESTE. PRODETUR I - Programa de Desenvolvimento do Turismo no Nordeste. Disponível em: <http://www.bnb.gov.br/prodetur/ne-i>. Acesso em: 20 maio 2015.

BANCO DO NORDESTE. PRODETUR II - Programa de Desenvolvimento do Turismo no Nordeste. Disponível em:< http://www.bnb.gov.br/prodetur/ne-ii $>$. Acesso em: 20 maio 2015.

BOYER, M. L'invention du tourisme. Paris: Gallimard, 1996. 2008. . Les villégiatures du XVIe au XXIe siècle. Caen: Management et Société,

CASTRO, I. E. Imaginário político e território. In: CASTRO, I. E.; GOMES, P. C. C.; CORRÊA, R. L. (Org.). Explorações geográficas. Rio de Janeiro: Bertrand Brasil, 1997.

CAZES, G. Les littoraux en proie au tourisme. Hérodote, n. 93, Paris: La Découverte, 1999.

CHARDON, J.-P. L'avion dans les Antilles. Bordeaux : CRET, 1987.

CLAVAL, P. La géographie culturelle. Paris: Nathan, 1995.

La fabrication du Brésil: une grande puissance en devenir. Paris: Belin, 2004.

CLAVAL, P.; SANGUIN, A. L. (Org.). Métropolisation et politique. Paris: L'Harmattan, 1997.

CORBIN, A. Le territoire du vide. Paris: Aubier, 1988.

História dos Tempos Livres. Lisboa: Teorema, 2001.

CORMIER-SALEM, M.-C. Maritimité et littoralité tropicales. In: Peron, F. et Rieucau, J. (Org.). La maritimité aujourd'hui. Paris: Ed. L'Harmattan, 1996. . Mar à vista. 2. ed. Fortaleza: Ed. UFC, 2011b. 
- Metropolização Turística em Região Monocultora Industrializada. Revista Mercator, v. 12, n. 2 (n. especial), 2013. p. 65-84. $63-76$. . O mar e o marítimo nos trópicos, GEOUSP, São Paulo, n. 15, 2004. p. La maritimité sous les Tropiques: les contributions d'une étude réalisée à Fortaleza (Ceará). Confins,Paris, v. 20, 2014. p. 1-15.

Tropism, the tourism greatest myth. In: CRAVIDÃO, F.; FERNANDES, J. A. R.; VALENÇA, M. M. (Org.). Regional and Urban Developments in PortugueseSpeaking Countries. New York: Nova Publishers, 2012.

DANTAS, E. W. C; ARAGAO, R. F.; LIMA, E. L. V.; THERY, H. Nordeste Brasileiro Fragmentado. In: SILVA, J. B. da.; DANTAS, E. W. C.; ZANELLA, E. Z.; MEIRELES, A. J. A. (Org.). Litoral e Sertão. Fortaleza: Expressão Gráfica, 2006b.

DANTAS, Eustógio W. C. De ressignificação das cidades litorâneas à metropolização turística. In: COSTA, Maria Clélia Lustosa \& PEQUENO, Renato. Fortaleza: transformações na ordem urbana. 1. ed. - Rio de Janeiro: Letra Capital: Observatório das Metrópoles, 2015.

DEMAJOROVIC, J; TUR, A. A.; LANDI, B.; KONDO, A. L. M. Complejos Turísticos Residenciales. Estudios y Perspectivas en Turismo, Buenos Aires, v. 20, n. 4, p. 772-796, 2011.

DESSE, M. L’inégale maritimité des villes des départements d'outre-mer insulaires. In: PERON, F.; RIEUCAU, J. (Org.). La maritimité aujourd'hui. Paris: Ed. L'Harmattan, 1996.

DOMENACH, J.-M. La propagande politique. Paris: Ed. PUF, 1979.

EVANS, N. H. La dynamique du développement du tourisme à Puerto Vallarta. In : KADT, E. (Org.). Le tourisme, passeport pour le développement. Paris: Ed. Économica, 1979.

FERREIRA, L. S. Culturas de Ordenamento Territorial do Turismo nas Regiões Metropolitanas de Fortaleza-CE, Natal-RN, Recife-PE e Salvador-BA. 2013. Tese (Doutorado em Geografia) - Departamento de Geografia, Universidade Federal do Ceará, Fortaleza, 2013.

FREYRE, G. Guia prático, histórico e sentimental da cidade do Recife. Recife: s. n., 1934.

GOMES, P. C. C. A condição urbana. Rio de Janeiro: Bertrand Brasil, 2002.

KADT, E. (Org.). Le tourisme, passeport pour le développement. Paris: Ed. Économica, 1979.

LEFEBVRE, H.. La production de l'espace. Paris: Anthropos, 1986.

LINHARES, P. Cidade de água e sal. Fortaleza: Fundação Demócrito Rocha, 1992.

MORAES, A. C. R. Contribuições para a gestão da zona costeira do Brasil. São Paulo: Annablume, 2007. 
MUNOZ, S. F.; TIMON, D. A. B. El Desarrollo Turístico Inmobiliario de laEspañaMediterráneay Insular frente a sus Referentes Internacionales (Florida y Costa Azul). Cuadernos de Turismo, Múrcia, n. 27, 2011.p. 373-402.

NIEVES, R. H. Tendencias del Turismo Residencial: el caso del mediterrâneo Español. El Periplo Sustentable, Toluca, n. 14, 2008. p. 65-87

NIJMAN, J. Miami. Philadelphia: University of Pennsylvania Press, 2010.

PEREIRA, A. Q. A Urbanização Vai à Praia. 2012. Tese (Doutorado em Geografia) - Departamento de Geografia, Universidade Federal do Ceará, Fortaleza, 2012.

SANTOS, M. O espaço dividido. São Paulo: Nobel, 1985.

SILVA, S. B. M.; CARVALHO, S. S. Vende-se uma região. Revista Desenbahia. Salvador, v. 8 n. 14, 2001. p. 99-114.

SILVA, K. O. A territorialização da residência secundária no litoral de Nísia Floresta (Rio Grande do Norte, Brasil). Turismo e Sociedade, Curitiba, v. 6, 2013. p. 58-78.

SOUSA, A. N. de. Orla oceânica de Salvador. Salvador: Ed. UFBA, 2011.

TORRES. E B. El Turismo Residenciado y sus Efectos en los Destinos Turísticos. Estudios Turisticos, Madrid, n. 155-156, 2003.p. 45-70.

VASCONCELOS, P. A. Os agentes modeladores das cidades brasileiras no período colonial. In: CASTRO, I. E.; GOMES, P. C. C.; CORRÊA, R. L. (Org.). Explorações geográficas. Rio de Janeiro: Bertrand Brasil, 1997.

WENDEL, H. Mercado imobiliário e mercantilização da natureza em Salvador e Região Metropolitana. Mercator, Fortaleza, v.10, n. 21, 2011. p. 63-80.

Eustógio Wanderley Correia Dantas - Possui Graduação em Geografia pela Universidade Estadual do Ceará. Mestrado em Geografia pela Universidade de São Paulo e Doutorado em Geografia pela Université ParisSorbonne. Atualmente é professor Titular da Universidade Federal do Ceará e do Programa de Pesquisa e Pós-Graduação em Geografia. Pesquisador do CNPq, 1D e Coordenador de Avaliação da área de Geografia da CAPES. 